\title{
The role of $\mathrm{Pb}^{2+}$ as a sensitizer for $\mathrm{Gd}^{3+}-\mathrm{Eu}^{3+}$ downconversion couple in fluorides
}

\author{
Vladimir Babin*, Koert D. Oskam, Peter Vergeer, Andries Meijerink \\ Chemistry and Physics of Condensed Matter, Debye Institute, Utrecht University, Princetonplein 5, Utrecht 3584 CC, The Netherlands
}

Received 27 November 2003; received in revised form 27 November 2003; accepted 7 December 2003

\begin{abstract}
Spectroscopic properties of $\mathrm{Pb}^{2+}$ in different fluoride host lattices were studied in order to investigate if $\mathrm{Pb}^{2+}$ can serve as a sensitizer for the $\mathrm{Gd}^{3+}-\mathrm{Eu}^{3+}$ quantum cutting system. Strong $\mathrm{B}^{\prime}$ emission of $\mathrm{Pb}^{2+}$ was found in several fluoride host lattices and for the first time $\mathrm{B}^{\prime}$ emission is reported at room temperature. It is shown that sensitization of the ${ }^{6} \mathrm{G}$ levels of $\mathrm{Gd}^{3+}$ is possible via $\mathrm{B}^{\prime}$ emission of $\mathrm{Pb}^{2+}$ in the host lattice $\left(\mathrm{BaF}_{2}\right)_{0.6}\left(\mathrm{GdF}_{3}\right)_{0.4}$ and visible quantum cutting with an efficiency of $20 \%$ is observed upon excitation in the $\mathrm{C}$ band of $\mathrm{Pb}^{2+}$. The possibility of sensitization of $\mathrm{Gd}^{3+}$ by $\mathrm{A}^{\prime}$ emission of $\mathrm{Pb}^{2+}$ in $\mathrm{KMgF}_{3}$ is discussed.
\end{abstract}

(c) 2004 Elsevier Ltd. All rights reserved.

Keywords: Luminescence; Downconversion; Sensitizer; Fluorides

\section{Introduction}

The finding of multi-photon emission through downconversion has provided new excitement in the search for phosphors with quantum efficiencies exceeding unity (Wegh et al., 1999). Visible quantum cutting phosphors are required for application in mercury-free fluorescent tubes and in plasma display panels. In these devices, the VUV radiation is generated by a noble gas $(\mathrm{Xe})$ discharge instead of conventional mercury. The couple $\mathrm{Gd}^{3+}-\mathrm{Eu}^{3+}$ offers the possibility to obtain efficiencies close to $200 \%$. Via a two-step energy transfer process one $\mathrm{Gd}^{3+}$ ion excited into the ${ }^{6} \mathrm{G}_{\mathrm{J}}$ level will relax yielding ${ }^{5} \mathrm{D}_{\mathrm{J}}$ emission from two $\mathrm{Eu}^{3+}$ ions. Due to the fact that absorption efficiency of the forbidden $\mathrm{f}-\mathrm{f}$ transitions in $\mathrm{Gd}^{3+}$ is low, the VUV radiation is only partly absorbed by $\mathrm{Gd}^{3+}$. Thus, a sensitizer is required which can absorb the VUV radiation and then transfer the energy to VUV levels of $\mathrm{Gd}^{3+}$. The requirements for sensitizer are: (i) absorption in the VUV range $(145-190 \mathrm{~nm}$ ); (ii) emission between 190 and $210 \mathrm{~nm}$ to

\footnotetext{
* Corresponding author. DESY HASYLAB, Notkestr. 85, 22603 Hamburg, Germany. Tel.: +49-40-8998-4526 fax: +49-40-8998-4475.

E-mail address: v.babin@phys.uu.nl (V. Babin).
}

have a good overlap with the ${ }^{6} \mathrm{G}$ levels of $\mathrm{Gd}^{3+}$; (iii) no quenching due to back transfer of the energy to sensitizer.

Heavy $\mathrm{s}^{2}$ ions have absorption and emission bands in the (V)UV, therefore they may be a good candidates for sensitization. The absorption properties of $\mathrm{s}^{2}$ ions are relatively well understood (Ranfagni et al., 1983). Upon promotion of an electron from the $s$ orbital to a $p$ orbital, 6s6p configurations arise. It gives rise to a triplet $\left({ }^{3} \mathrm{P}_{0,1,2}\right)$ and singlet $\left({ }^{1} \mathrm{P}_{1}\right)$ terms. Transitions to the lower energy triplet excited states $\left({ }^{3} \mathrm{P}_{0,1,2}\right)$ are spin forbidden, but due to spin-orbit coupling the transitions to the ${ }^{3} \mathrm{P}_{1}$ and ${ }^{3} \mathrm{P}_{2}$ are relatively intense. The transition to the ${ }^{1} \mathrm{P}_{1}$ state is fully allowed. In absorption spectrum the transitions to the ${ }^{3} \mathrm{P}_{1},{ }^{3} \mathrm{P}_{2}$ and ${ }^{1} \mathrm{P}_{1}$ states are labeled in order of increasing energy by $\mathrm{A}, \mathrm{B}$ and $\mathrm{C}$ bands. A fourth state is assigned to a charge transfer-type transition and is labelled as D (Folkerts et al., 1995). The emission usually occurs from the ${ }^{3} \mathrm{P}_{0,1}$ state $\left(\mathrm{A}^{\prime}\right.$ emission). Often the A band is split into two bands due to dynamic Jahn-Teller effect (Ranfagni et al., 1983). In few cases the ${ }^{3} \mathrm{P}_{2}$ ( $\mathrm{B}^{\prime}$ band) emission has been observed at low temperatures (Oboth et al., 1989). In the electronic transitions of $\mathrm{Pb}^{2+}$ non-shielded $\mathrm{s}$ and $\mathrm{p}$ orbitals are involved. This means that the positions of the absorption and emission bands, Stokes shift and quenching temperature of the emission vary strongly as a function of host lattice. The highest 
energy sp excited states are found in fluorides, and $\mathrm{Pb}^{2+}$ ion has the sp excited state at the highest energies in comparison to other $\mathrm{s}^{2}$ ions. Therefore, it can be an ideal sensitizer for the $\mathrm{Gd}^{3+}{ }^{6} \mathrm{G}$ level. In the past only a few studies have investigated the VUV luminescence of $\mathrm{Pb}^{2+}$. A systematic VUV spectroscopic investigations of $\mathrm{Pb}^{2+}$ in earth alkaline fluorides has been performed by Oboth et al. (1989).

In this paper, luminescent characteristics of $\mathrm{Pb}^{2+}$ in various fluorides were studied in order to clarify its role as a possible sensitizer for the $\mathrm{Gd}^{3+}-\mathrm{Eu}^{3+}$ downconversion couple.

\section{Experimental}

Measurements were performed on crystalline powder samples. $\mathrm{MF}_{2}(\mathrm{M}=\mathrm{Ba}, \mathrm{Sr}, \mathrm{Ca}), \mathrm{LnF}_{3}(\mathrm{Ln}=\mathrm{La}, \mathrm{Y}, \mathrm{Gd})$ and $\mathrm{KMgF}_{3}$ samples doped with $\mathrm{PbF}_{2}(0.2-1 \mathrm{~mol} \%$ ) were obtained by adding $\mathrm{PbF}_{2}$ to the pure host materials, mixing and firing in an alumina crucible (typically $4-5 \mathrm{~h}$ at 900 $-1000 \mathrm{~K})$ in nitrogen atmosphere. To avoid the formation of oxides and hydroxides in the samples, $\mathrm{NH}_{4} \mathrm{~F}$ was added to the mixture and in the oven a crucible with $\mathrm{KF}_{2} \mathrm{H}$ was placed. Samples of the binary fluoride compounds $\left(\mathrm{MF}_{2}\right)_{1-x}\left(\mathrm{YF}_{3}\right)_{x}$ doped with $\mathrm{Pb}^{2+}$ (including $\mathrm{BaY}_{2} \mathrm{~F}_{8}$ ) were prepared by thoroughly grinding stoichiometric amounts of the appropriate starting compounds. The firing procedure was the same (at $1100 \mathrm{~K}$ ). In the synthesis of $\mathrm{LiBaF}_{3}$ an excess amount of LiF was used. After synthesis, all samples were checked by using X-ray diffraction method.

Spectroscopic investigations were performed on two different setups in temperature range from 10 to $300 \mathrm{~K}$. For low resolution luminescence investigations a VUV-adapted spectrofluorometer, equipped with double monochromators and deuterium lamp was used. Excitation and emission spectra were corrected for the lamp intensity and the transmission of the monochromators. The high-resolution measurements were carried out at HIGITI experimental station of HASYLAB at DESY, Hamburg. The excitation spectra of various emissions were normalized to equal quantum intensities of synchrotron radiation falling onto a sample. Both experimental setups are described extensively in detail in Wegh et al. (1997).

\section{Results and discussion}

The positions of excitation and emission bands in all $\mathrm{MF}_{2}$ compounds doped with $\mathrm{Pb}^{2+}$ agree very well with the values given by Oboth et al. (1989). Peaks positions and Stokes' shift, as determined by our investigations are given in Table 1 for all compounds studied. As an example, Fig. 1 displays luminescence spectra for $\mathrm{CaF}_{2}: \mathrm{Pb}^{2+}$. The excitation spectrum monitoring $\mathrm{A}^{\prime}$ emission and emission spectrum, upon excitation in the $\mathrm{C}$ band are shown and the bands are assigned in the figure. In addition to the emission

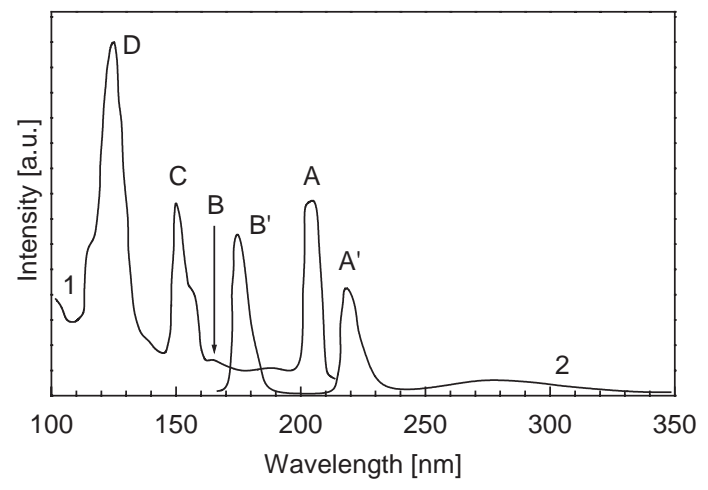

Fig. 1. Excitation spectrum (curve 1) of $\mathrm{CaF}_{2}: \mathrm{Pb}^{2+}$ monitoring the $\mathrm{A}^{\prime}$ emission $(219 \mathrm{~nm}$ ) and emission spectrum (curve 2) upon excitation the $\mathrm{C}$ band $(151 \mathrm{~nm})$ at $10 \mathrm{~K}$.

bands described in Oboth et al. (1989), a broad band is observed in the UV region, peaking at $275 \mathrm{~nm}$. This band is ascribed to a host lattice-related emission and similar features are observed in all fluoride samples doped with $\mathrm{Pb}^{2+}$ described in this article which were prepared in the same manner. The spectra of $\mathrm{SrF}_{2}: \mathrm{Pb}^{2+}$ and $\mathrm{BaF}_{2}: \mathrm{Pb}^{2+}$ resemble those of $\mathrm{CaF}_{2}: \mathrm{Pb}^{2+}$. The splitting of the $\mathrm{A}^{\prime}$ band of $\mathrm{Pb}^{2+}$, hardly visible in $\mathrm{CaF}_{2}$, is more pronounced in $\mathrm{SrF}_{2}$ and $\mathrm{BaF}_{2}$ while the emission bands are shifted to longer wavelengths as the ionic radius of the alkaline earth ion increases.

Upon excitation of $\left(\mathrm{CaF}_{2}\right)_{0.7}\left(\mathrm{YF}_{3}\right)_{0.3}: \mathrm{Pb}^{2+}$ in the $\mathrm{A}$ band, two emission bands are observed in the UV region. The band peaking at $246 \mathrm{~nm}$ is assigned to the $\mathrm{A}^{\prime}$ emission. The excitation spectrum of the $A^{\prime}$ emission shows a (Jahn-Teller) split A band and a complex broad band at $\lambda<165 \mathrm{~nm}$. This band contains the $\mathrm{B}, \mathrm{C}$ and $\mathrm{D}$ bands. A strong $\mathrm{B}^{\prime}$ emission is observed upon excitation at 140 $\mathrm{nm}$. From the excitation spectra of $\mathrm{A}^{\prime}$ and $\mathrm{B}^{\prime}$ bands the exact positions of $\mathrm{B}, \mathrm{C}$ and $\mathrm{D}$ bands cannot be determined. The spectra of $\left(\mathrm{SrF}_{2}\right)_{0.7}\left(\mathrm{YF}_{3}\right)_{0.3}: \mathrm{Pb}^{2+}$ are similar to those of $\left(\mathrm{CaF}_{2}\right)_{0.7}\left(\mathrm{YF}_{3}\right)_{0.3}: \mathrm{Pb}^{2+}$, but the splitting of the $\mathrm{B}, \mathrm{C}$ and $\mathrm{D}$ bands is more pronounced. The intensity of the $\mathrm{B}^{\prime}$ band with respect to the $\mathrm{A}^{\prime}$ band decreases gradually with increasing temperature, but $\mathrm{B}^{\prime}$ emission is still present at room temperature. $\left(\mathrm{SrF}_{2}\right)_{0.7}\left(\mathrm{YF}_{3}\right)_{0.3}: \mathrm{Pb}^{2+}$ shows a temperature-dependent behaviour similar to $\mathrm{CaF}_{2}$.

In the spectra of $\mathrm{YF}_{3}: \mathrm{Pb}^{2+}$ two $\mathrm{A}$ excitation bands are observed. The $\mathrm{C}$ band in this compound is very intense. The B band is not clearly observed, but is probably positioned as a shoulder on the long-wavelength side of the $\mathrm{C}$ band. The D excitation band shows complicated structure with several overlapping bands. The peak at $110 \mathrm{~nm}$ is assigned to the host lattice absorption. No $\mathrm{B}^{\prime}$ emission is observed in $\mathrm{YF}_{3}: \mathrm{Pb}^{2+}$. In the emission spectra of $\mathrm{GdF}_{3}: \mathrm{Pb}^{2+}$, only emissions from $\mathrm{Gd}^{3+}$ levels are observed upon excitation in all levels of $\mathrm{Pb}^{2+}$. The excitation 
Table 1

Peak positions of excitation $\left(\mathrm{A}_{1}, \mathrm{~A}_{2}, \mathrm{~B}, \mathrm{C}\right.$ and $\left.\mathrm{D}\right)$ and emission $\left(\mathrm{A}^{\prime}\right.$ and $\left.\mathrm{B}^{\prime}\right)$ bands (in $\left.\mathrm{nm}\right)$ of the $\mathrm{Pb}^{2+}$ emissions in various fluoride host lattices at $10 \mathrm{~K}$. For $\mathrm{BaY}_{2} \mathrm{~F}_{8}$, the data for two different $\mathrm{Pb}^{2+}$ sites (I and II) are shown (see text)

\begin{tabular}{|c|c|c|c|c|c|c|c|}
\hline & $\mathrm{A}_{1}$ & $\mathrm{~A}_{2}$ & B & $\mathrm{C}$ & $\mathrm{D}$ & $\mathrm{A}^{\prime}$ & $\mathrm{B}^{\prime}$ \\
\hline $\mathrm{CaF}_{2}$ & 205 & & 165 & 151 & 128 & 219 & 176 \\
\hline $\mathrm{SrF}_{2}$ & 204 & 201 & 165 & 155 & 134 & 223 & 177 \\
\hline $\mathrm{BaF}_{2}$ & 203 & 201 & 165 & 156 & 136 & 260 & 189 \\
\hline $\mathrm{YF}_{3}$ & 210 & 196 & 170 & 162 & $\sim 140$ & 288 & \\
\hline $\mathrm{GdF}_{3}$ & 206 & 195 & 170 & 163 & 142 & & \\
\hline $\mathrm{LaF}_{3}$ & 200 & 193 & & 159 & 142 & 280 & \\
\hline$\left(\mathrm{CaF}_{2}\right)_{0.7}\left(\mathrm{YF}_{3}\right)_{0.3}$ & 192 & 186 & $<165$ & $<155$ & $<145$ & 246 & 180 \\
\hline$\left(\mathrm{SrF}_{2}\right)_{0.7}\left(\mathrm{YF}_{3}\right)_{0.3}$ & 199 & 193 & 163 & 154 & $<150$ & 239 & 181 \\
\hline \multirow{2}{*}{$\begin{array}{ll}\mathrm{BaY}_{2} \mathrm{~F}_{8} & \text { site I } \\
& \text { site II }\end{array}$} & 187 & 184 & 156 & 148 & 140 & 228 & 175 \\
\hline & 200 & & 172 & 167 & 149 & 289 & 200 \\
\hline $\mathrm{LiBaF}_{3}$ & 191 & & 158 & 154 & 141 & 247 & 185 \\
\hline $\mathrm{KMgF}_{3}$ & 187 & & 154 & 138 & 127 & 217 & 169 \\
\hline
\end{tabular}

spectra of these $\mathrm{Gd}^{3+}$ emissions clearly show the absorption bands of $\mathrm{Pb}^{2+}$ with strong intensity. They show great similarity with the excitation spectra of the $\mathrm{A}^{\prime}$ emission of $\mathrm{YF}_{3}$, although the bands are found at somewhat shorter wavelengths (see Table 1). Emission is observed from the ${ }^{6} \mathrm{D}(\sim 255 \mathrm{~nm}),{ }^{6} \mathrm{I}(\sim 280 \mathrm{~nm})$ and ${ }^{6} \mathrm{P}(\sim 310 \mathrm{~nm})$ levels of $\mathrm{Gd}^{3+}$, which means that energy transfer from $\mathrm{Pb}^{2+}$ to $\mathrm{Gd}^{3+}$ takes place via the $\mathrm{A}^{\prime}$ emission of $\mathrm{Pb}^{2+}$. Excitation bands of $\mathrm{Pb}^{2+}$ in $\mathrm{LaF}_{3}$ are found at even higher energies (see Table 1). The Stokes shift of the $\mathrm{A}^{\prime}$ emission is rather large.

Spectroscopic analysis shows that there are at least two sites for $\mathrm{Pb}^{2+}$ in $\mathrm{BaY}_{2} \mathrm{~F}_{8}: \mathrm{Pb}^{2+}$ (see Table 1). The positions of the excitation bands are at high energy compared to those in other fluorides (site I). The A band is split with maxima at 187 and $184 \mathrm{~nm}$. The corresponding $\mathrm{A}^{\prime}$ emission is observed at $228 \mathrm{~nm}$. In the excitation spectrum of the intense $\mathrm{B}^{\prime}$ emission at $175 \mathrm{~nm}$, the $\mathrm{B}$ and $\mathrm{C}$ bands are observed. The spectral behaviour of the bands does not depend on the $\mathrm{Pb}^{2+}$ concentration. The intensity of $\mathrm{B}^{\prime}$ emission ( site I) remains strong at room temperature. The intensity of $\mathrm{B}^{\prime}$ ( site II) decreases with increasing temperature and disappears above $200 \mathrm{~K}$. The luminescence decay time for the $\mathrm{B}^{\prime}$ emission is $149 \mathrm{~ns}$ at $10 \mathrm{~K}$ and $93 \mathrm{~ns}$ at $100 \mathrm{~K}$.

No splitting is observed for the $\mathrm{A}$ band in $\mathrm{LiBaF}_{3}$. The excitation bands are at relatively high energy. The B band is seen as a shoulder on the longer wavelength side of the $\mathrm{C}$ band. In emission spectra upon excitation in $\mathrm{C}$ band, $\mathrm{B}^{\prime}$ and $\mathrm{A}^{\prime}$ emissions are observed. The decay time of the $\mathrm{B}^{\prime}$ emission is $165 \mathrm{~ns}$ at $10 \mathrm{~K}$. $\mathrm{B}^{\prime}$ emission is not observed at temperatures higher than $210 \mathrm{~K}$.

In $\mathrm{KMgF}_{3}$ the $\mathrm{Pb}^{2+}$ ion substitutes the $\mathrm{K}^{+}$ion on the large site with a cubic 12 -fold $\mathrm{F}^{-}$coordination. On this large site the $\mathrm{A}, \mathrm{B}$ and $\mathrm{C}$ absorption bands are at the highest energies in comparison with the other fluoride host lattices. The $\mathrm{A}^{\prime}$ emission band has a maximum at $217 \mathrm{~nm}$ and has a good spectral overlap on the short-wavelength side with the $\mathrm{Gd}^{3+}$ excitation lines around $205 \mathrm{~nm}\left({ }^{6} \mathrm{G}_{\mathrm{J}}\right.$ levels $)$. The A band in the excitation spectrum is situated at too high energies to allow for back transfer. Thus, among all fluorides studied, only in $\mathrm{KMgF}_{3}$ the $\mathrm{A}^{\prime}$ emission band of $\mathrm{Pb}^{2+}$ fulfills the conditions for a good sensitizer for the ${ }^{6} \mathrm{G}$ levels of $\mathrm{Gd}^{3+}$. Unfortunately, it is not possible to incorporate a large amount of $\mathrm{Gd}$ and $\mathrm{Eu}$ in the $\mathrm{KMgF}_{3}$ lattice. Therefore, a host lattice with a similar large (12 coordinated) site for $\mathrm{Pb}^{2+}$ has to be found in which also trivalent ions like $\mathrm{Gd}^{3+}$ and $\mathrm{Eu}^{3+}$ can be incorporated.

An alternative is sensitization of the ${ }^{6} \mathrm{G}$ levels of $\mathrm{Gd}^{3+}$ via $\mathrm{B}^{\prime}$ band emission. This has been studied in the $\mathrm{BaF}_{2}-$ $\mathrm{GdF}_{3}$ system. The amount of $40 \% \mathrm{GdF}_{3}$ is the maximum that can be incorporated in this lattice without getting a second phase. To ensure that the energy migration over the different levels of $\mathrm{Gd}^{3+}$ can occur (required for the quantum cutting process), measurements were done on samples with $40 \%$ of $\mathrm{Gd}^{3+}$. When the compound is doped with only $\mathrm{Eu}^{3+}$ (no $\mathrm{Pb}^{2+}$ added), the relative emission intensity of the ${ }^{5} \mathrm{D}_{0}$ emissions compared to the other ${ }^{5} \mathrm{D}_{\mathrm{J}}$ emissions increases upon excitation in the ${ }^{6} \mathrm{G}_{\mathrm{J}}$ levels of $\mathrm{Gd}^{3+}$ in comparison with the spectrum for ${ }^{6} \mathrm{I}$ excitation (Fig. 2). This is characteristic for the presence of quantum cutting and following the method of Wegh et al. (1999), we determined from the integrated emission intensities a quantum cutting efficiency of $50 \%$, i.e. a total quantum efficiency through downconversion can be as high as $150 \%$. In the compound with $\mathrm{Pb}^{2+}$ quantum cutting is also observed upon excitation of $\mathrm{Pb}^{2+}$ in the VUV. By comparing the relative intensities of the ${ }^{5} \mathrm{D}_{0}$ and ${ }^{5} \mathrm{D}_{\mathrm{J}}$ emissions of $\mathrm{Eu}^{3+}$ upon excitation in the $\mathrm{C}$ band of $\mathrm{Pb}^{2+}$ and in the ${ }^{6} \mathrm{I}$ level of $\mathrm{Gd}^{3+}$, we estimate a quantum cutting efficiency to be $20 \%$. The lower downconversion efficiency in this system is explained by the fact that the $\mathrm{A}$ band of $\mathrm{Pb}^{2+}$ overlaps with ${ }^{6} \mathrm{G}$ levels of $\mathrm{Gd}^{3+}$, which causes energy back transfer from $\mathrm{Gd}^{3+}\left({ }^{6} \mathrm{G}\right)$ to $\mathrm{Pb}^{2+}$. This process competes with the downconversion process from the ${ }^{6} \mathrm{G}$ level. 


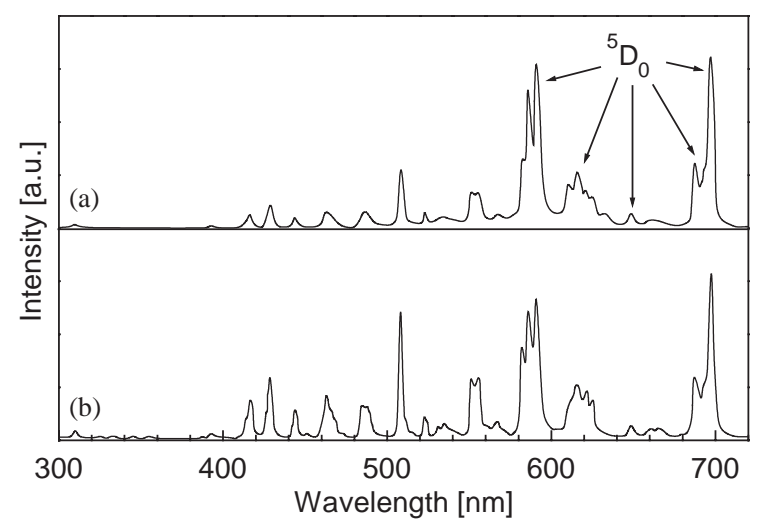

Fig. 2. Emission spectrum of $\left(\mathrm{BaF}_{2}\right)_{0.6}\left(\mathrm{GdF}_{3}\right)_{0.4}: \mathrm{Eu}^{3+}$ upon excitation in (a) ${ }^{6} \mathrm{G}$ level $(184 \mathrm{~nm})$ and (b) ${ }^{6}$ I level $(273 \mathrm{~nm})$ of $\mathrm{Gd}^{3+}$.

\section{Conclusions}

Research on $\mathrm{s}^{2}$ ions can result in finding a good sensitizer for the $\mathrm{Gd}^{3+}{ }^{6} \mathrm{G}$ level. Luminescence spectroscopy for $\mathrm{Pb}^{2+}$ in a variety of fluoride crystals shows that in some fluorides high-energy (VUV) B-band emission is observed, even at $300 \mathrm{~K}$. This B-band emission is also observed to sensitize the ${ }^{6} \mathrm{G}$ level of $\mathrm{Gd}^{3+}$ but back-transfer from the ${ }^{6} \mathrm{G}$ level of $\mathrm{Gd}^{3+}$ to the A-band of $\mathrm{Pb}^{2+}$ competes with the quantum cutting process. In $\mathrm{KMgF}_{3}$ the energy level structure of the $\mathrm{Pb}^{2+}$ ion resembles that of the ideal sensitizer for the ${ }^{6} \mathrm{G}$ level of $\mathrm{Gd}^{3+}$. The A-band is at the highest energy known for $\mathrm{Pb}^{2+}$ and is situated above the ${ }^{6} \mathrm{G}$ level of $\mathrm{Gd}^{3+}$. This prevents the undesired back-transfer. Further research should be focused at finding host lattices where (i) the B band emission is not quenched at room temperature and with a proper tuning of the A band (no absorption around $205 \mathrm{~nm}$ ), or, alternatively, (ii) the $\mathrm{A}^{\prime}$ band is located at high energy enough to overlap with the ${ }^{6} \mathrm{G}$ levels of $\mathrm{Gd}^{3+}$. In this case a host lattice with trivalent cation sites (for $\mathrm{Gd}^{3+}$ and $\mathrm{Eu}^{3+}$ ) and large divalent cation sites, resembling the $\mathrm{K}^{+}$site in $\mathrm{KMgF}_{3}$, is the most promising.

\section{Acknowledgements}

This project is supported by Philips Lighting, Eindhoven and Dutch STW project no. 349-5086. Authors are grateful to Prof. C. Ronda and Dr. C. Feldmann from Philips Research, Aachen; Dr. S. Poort, Dr. B. Smet and Dr. J. de Hair from Philips Lighting, Eindhoven for discussions. Dr. P. Gürtler from HASYLAB at DESY, Hamburg; Dr. L. van Pieterson and P. Peijzel from Utrecht Univesrity are acknowledged for help with experiments.

\section{References}

Folkerts, H.F., Hamstra, M.A., Blasse, G., 1995. The luminescence of $\mathrm{Pb}^{2+}$ in alkaline earth sulfates. Chem. Phys. Lett. 246, $135-138$.

Oboth, K.P., Lohmeier, F.J., Fischer, F., 1989. VUV and UV spectroscopy of $\mathrm{Pb}^{2+}$ and $\mathrm{Bi}^{3+}$ centres in alkaline-earth fluorides. Phys. Stat. Sol. B 154, 789-803.

Ranfagni, A., Mugnai, D., Bacci, M., Viliani, G., Fontana, M.P., 1983. The optical properties of thallium-like impurities in alkali-halide crystals. Adv. Phys. 32, 823-905.

Wegh, R.T., Donker, H., Meijerink, A., Lamminmäki, R.J., Hölsä, J., 1997. Vacuum-ultraviolet spectroscopy and quantum cutting for $\mathrm{Gd}^{3+}$ in $\mathrm{LiYF}_{4}$. Phys. Rev. B 56, 13841-13848.

Wegh, R.T., Donker, H., Oskam, K.D., Meijerink, A., 1999. Visible quantum cutting in $\mathrm{LiGdF}_{4}: \mathrm{Eu}^{3+}$ through downconversion. Science 283, 663-666. 